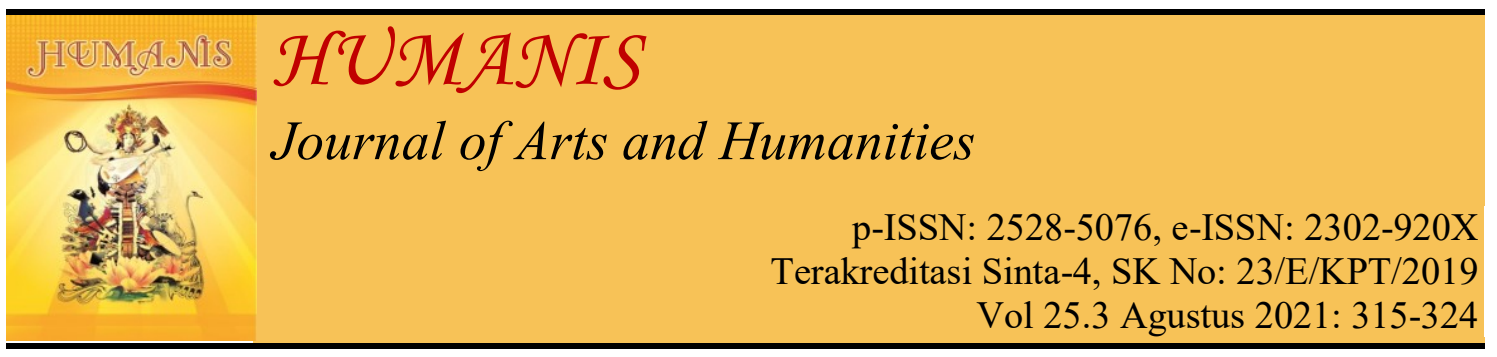

\title{
Dunia Fauna Kumpulan Puisi Jantung Lebah Ratu
}

\author{
Chresna Satyavadini \\ Universitas Udayana, Denpasar, Bali \\ Email korespondensi: chresnasatya30@gmail.com
}

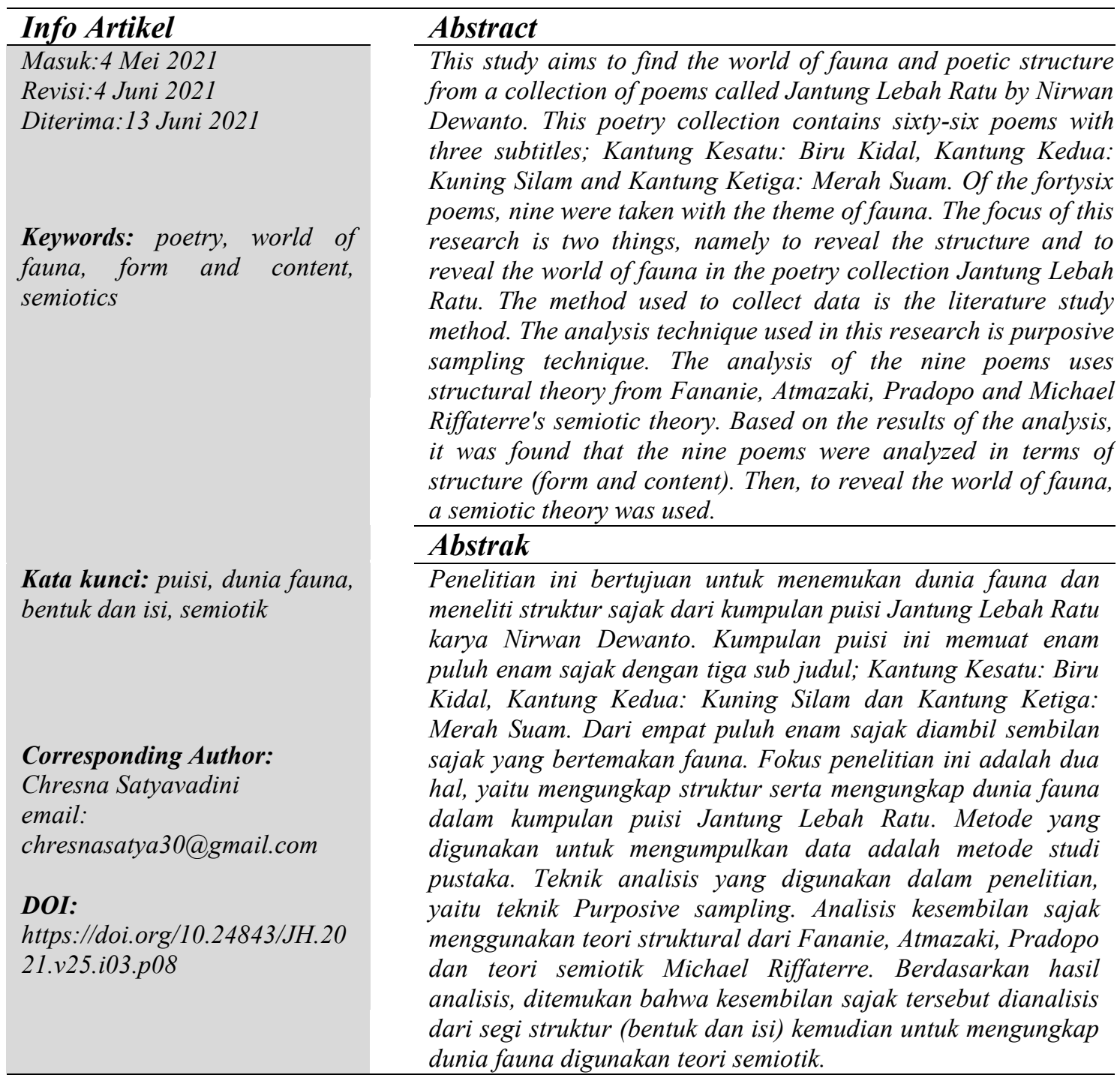

\section{PENDAHULUAN}

Puisi Indonesia dalam perkembangannya dari tahun 1920-an hingga kini mengalami perkembangan dinamis dalam hal isi dan bentuk. Gayagaya penulisan puisi lama yang mengutamakan irama seperti dalam pantun dan syair mendominasi puisi 
penyair Angkatan Pujangga Baru, sedangkan bentuk-bentuk modern dan bebas ikatan mewarnai karakter puisi Angkatan 1945. Dinamika itu terus terjadi pada karya-karya penyair Angkatan 66 dan Angkatan pascareformasi. Walaupun bentuk puisi bebas dominan, keindahan irama yang mengingatkan ciri syair dan pantun kembali muncul dalam puisi-puisi liris penyair dewasa ini, seperti terlihat dalam karya-karya Sapardi Djoko Damono, Joko Pinurbo, dan Nirwan Dewanto. Meskipun mengadopsi gaya puisi lama, karya mereka tetap unik dan merefleksikan jati diri kekhasan penyair masing-masing.

P.M Anastasia dkk. (2016) menyatakan setiap penyair memiliki ciri khas dalam proses menciptakan puisi. Ciri tersebut dapat diamati melalui bentuk dan isi puisi. Bentuk berkaitan dengan bunyi, diksi, bahasa kiasan, dan citraan, sedangkan isi berkaitan dengan makna. Prinsip dasar sebuah puisi adalah berkata sedikit, tetapi memiliki makna yang luas (Dewi dkk., 2017). Sebuah kumpulan puisi memiliki bentuk yang beragam, salah satunya kumpulan puisi Jantung Lebah Ratu (2008) karya Nirwan Dewanto.

Jantung Lebah Ratu adalah kumpulan puisi karya Nirwan Dewanto yang diterbitkan pada 2008 oleh Gramedia Pustaka Utama. Kumpulan ini ditulis tahun 2005 hingga 2007 dengan jumlah halaman 94, yang memuat 46 puisi. Puisi-puisi itu dikelompokkan menjadi tiga bagian. Bagian pertama Kantung Kesatu: Biru Kidal, Kantung Kedua: Kuning Silam dan Kantung Ketiga: Merah Suam.

Penelitian ini meneliti sembilan puisi bertemakan fauna. Kumpulan puisi Jantung Lebah Ratu dijadikan objek penelitian dengan alasan yaitu dari aspek bentuk yang digunakan penyair sangat khas. Ia mampu menghidupkan beragam jenis fauna secara detail, deskriptif sehingga memunculkan efek estetis. Kumpulan puisi Jantung Lebah Ratu mendapatkan penghargaan sebagai pemenang Khatulistiwa Literary Award (KLA) untuk kategori puisi pada 13 November 2008 di Jakarta.

Penelitian ini bertujuan untuk mengetahui bentuk dan isi kesembilan sajak. Selain itu penelitian ini bertujuan untuk mengetahui dunia fauna kesembilan sajak yang digambarkan dalam kumpulan puisi Jantung Lebah Ratu.

\section{METODE DAN TEORI}

Metode yang digunakan dalam tahapan pengumpulan data adalah metode studi pustaka. Teknik yang digunakan untuk menganalisis data yaitu teknik baca, simak, dan catat. Berikutnya menganalisis data dengan mengelompokkan sesuai dengan katagori yang diinginkan. Pada penelitian ini digunakan metode dan teknik pengolahan data berupa metode deskripsi analisis dan teknik hermeneutika. Tahapan penyajian hasil analisis data menggunakan metode deskriptif, yaitu dengan penggunaan bahasa Indonesia ragam ilmiah. Hasil analisis data ditulis dalam format skripsi.

Teori yang digunakan yaitu teori struktural dan semiotik. Teori struktural yang digunakan adalah teori yang disampaikan oleh Fananie dalam Telaah Sastra dan teori dari Atmazaki dalam Analisis Sajak, sedangkan semiotik menggunakan teori yang disampaikan oleh Michael Riffaterre dalam Teori dan Aplikasi Semiotik. Kedua teori tersebut menjadi penunjang untuk menganalisis kesembilan puisi

\section{HASIL DAN PEMBAHASAN}

Hasil dan pembahasan dalam penelitian ini diuraikan berdasarkan penelitian yang telah dilakukan. 


\section{Diksi}

Wirandika (2014) menyatakan bahwa puisi sebagai sebuah karya sastra bukan merupakan deretan kata-kata, tetapi tiap kata adalah hasil dari ekspresi jiwa, imajinasi, dan pengalaman jiwa yang diungkapkan secara matang oleh penyair. Fananie (2001) mengungkapkan bahwa diksi (pilihan kata) adalah hal yang esensial dalam struktur puisi, karena kata merupakan wahana ekspresi utama. Meliala dkk. (2018) menyatakan bahwa diksi juga digunakan untuk mengongkretkan penjelasan pengarang. Diksi yang ditemukan dalam kumpulan puisi Jantung Lebah Ratu terdiri atas blank symbol, natural symbol dan private symbol.

Diksi blank symbol atau simbol dengan mekna yang bersifat universal. Meskipun maknanya bersifat konotatif, tetapi pembaca tidak perlu menafsirkannya karena acuan maknanya sudah bersifat umum (Gunawan \& Sujinah, 2018). Sebagai contoh pada sajak Kunang-Kunang ditemukan blank symbol /merah darah/, dan /hitam legam/. Diksi natural symbol atau simbol realitas alam juga ditemukan. Sebagai contoh pada sajak Cumi-Cumi ditemukan natural symbol /duri bintang/, /debu bulan/ dan /gugus terumbu/. Diksi private symbol atau simbol khusus yang diciptakan penyair juga ditemukan. Sebagai contoh pada sajak Ubur-Ubur ditemukan private symbol/perenang buta/, /gerimis mei/, dan kitab biologi/.

\section{Bunyi}

Bunyi adalah salah satu hal terpenting dalam sajak karena munculnya bunyi dalam sajak akan mempengaruhi efek dan kesan dalam sajak tersebut. Bunyi yang berperan pada sajak adalah bunyi yang terpola (Atmazaki, 1993). Unsur bunyi berperan untuk memberi pengaruh dan sugesti kepada pembaca dan penikmatnya (Yudha dkk., 2019).

Bunyi yang ditemukan dalam penelitian ini, yaitu asonansi, aliterasi, rima dalam, rima akhir, dan anfora. Asonansi yang ditemukan adalah asonansi bunyi $a, i$ dan $u$. Asonansi $a$ banyak ditemukan pada sajak CumiCumi. Sebagai contoh:

\section{Seperti saputangan i $a$ yang terkoyak di satu sudutnya ketika terantuk gugus terumbu saputangan tembus-cahay $a$ karena kenyang oleh airmat $a$}

Selain sajak cumi-cumi, ditemukan asonansi $a$ pada sajak Ular. Asonansi $a$ terletak pada baris kedua, kelima, keenam, kedua puluh tiga sampai kedua puluh tujuh dan ketiga puluh satu sampai ketiga puluh tiga, /agar mereka lebih remaja, pun lebih dahaga/, /sebab aku tahu sang Wajah nun di sana/, /akan menjadikan mereka sekadar ibu-bapa/, /Lebih adil lagi, kubimbing keduanya/, /ke pohon gelap maupun pohon cahayal, /Pilihlah sendiri buah mana paling sembada/, /bila lidahmu luka, mahirlah kau berbahasa/, /bila kau kenyang, mungkin kau akan binasa/, /akan kubasuh mereka, meski mereka/, /hanya dahaga, akan kulepas mereka/, /agar aku melingkar sempurnal. Berikutnya asonan-si $i$ ditemukan juga pada sajak Ular. Asonansi $i$ terletak pada baris keempat belas, kelima belas, ketiga puluh lima, ketiga puluh enam /oleh khazanah yang membayang sesekali/, /dari balik batas: itulah mungkin Laut Mati/, /barisan gandum dan sesawi, lalu menyalakan api/, /yang menarik wajahku kemari/. Asonansi $u$ ditemukan pada sajak Harimau. Sebagai contoh:

ketika kau perawankan tubuhm $u$ ketika bundaku menjadi bundam $u$ 
Selanjutnya unsur bunyi lain yang ditemukan adalah aliterasi, rima dalam, rima akhir dan anafora. Aliterasi adalah repetisi konsonan pada awal kata secara berurutan (Fitriyah, 2018). Sajak Kunang-Kunang contohnya, ditemukan aliterasi $b, m, s$ dan $z$. Aliterasi $b$ ditemukan pada bait kedua /Baraku biru, begitu biru/. Aliterasi $m$ pada bait kedelapan /membenturku, meremukanku, menyerakkanku/. Aliterasi s pada bait kedua /sehingga sebatang sungai/. Aliteras $z$ pada bait kesembilan /zarah atau zuhrah/. Unsur bunyi rima dalam dan rima akhir salah satunya terdapat pada bait kelima sajak Lebah Ratu. Rima dalam /ru/ terdapat pada bait kelima /seluruh kami, bahkan seluruh seterumu/. Rima akhir/ng/ pada /yang gugur adalah bayang-bayangmu sendiri, yang mencoba lebih nyata ketimbang citramu/. Amin \& Usman (2018) menyatakan bahwa anafora merupakan bagian dari gaya bahasa dengan ciri khas menggunakan kata-kata yang diulang-ulang. Contoh anafora ditemukan pada sajak Akuarium.

mata tengah malam

mata yang berenang-renang ke tepian

mata yang bersisik seperti sedia kala

mata yang girang kauperangkap

mata yang kehilangan ekor mata

\section{Citraan}

Laila (2016) menyatakan bahwa citraan atau pengimajian adalah gambargambar dalam pikiran, atau gambaran angan si penyair. Setiap gambar pikiran disebut citra atau imaji (image). Bentuk citraan yang ditemukan adalah citraan penglihatan, gerak dan pendengaran. Sebagai contoh pada sajak Ubur-Ubur. Citraan penglihatan terdapat pada baris pertama dan kedua /ia mata-mata hanya terpindai di antara nisan batukarang dan gaun ganggang/, citraan pendengaran ditemukan pada baris keempat sampai keenam /ia jantung hati, berdegup di antara pipi hiu dan punggung perenang buta/, dan citraan gerak ditemukan pada baris ketujuh /gemar melayang dengan lebat racun/.

\section{Bahasa Kiasan}

Bahasa kiasan dipergunakan untuk memperbesar kepuitisan sajak, mendapat-kan gambaran yang konkret, jelas ataupun gambaran yang segar dan hidup. Dapat dikatakan bahwa bahasa kiasan adalah sarana utama untuk mencapai kepuitisan (Saptawuryandari, 2013). Bahasa kiasan juga sebuah cara untuk mengungkapkan sesuatu di luar cara yang biasanya menurut Perrine dalam (Lotia, 2016). Bahasa kiasan yang ditemukan dalam analisis diantaranya bahasa kiasan personifikasi, metafora, hiperbola, simile, dan allegori. Bahasa kiasan simile, metafora dan allegori ditemukan pada sajak Cumi-Cumi. Bahasa kiasan simile ditemukan pada baris pertama /seperti saputangan ia/ yang menggambarkan bentuk cumi-cumi serupa saputangan. Bahasa kiasan metafora ditemukan pada baris ketiga puluh.

/sehingga tubuh si penyelam menjadi sebening udara pagi/, menjelaskan bagaimana si penyelam merasakan keindahan yang menawarkan suasana sejuk. Bahasa kiasan allegori yang memunculkan penafsiran sajak cumi-cumi ditemukan pada baris ketiga puluh sembilan sampai baris keempat puluh dua.

/Kukira seekor cumi-cumi menjelma sehelai saputangan karena ia selalu dahaga akan matamu, airmatamu/

Bahasa kiasan personifikasi ditemukan pada bait kenam sajak Burung Merak/Suatu hari si rajawali yang mulai belajar bertepuk tangan/, rajawali yang memiliki sayap digambarkan berperilaku sebagai-mana manusia (tepuk tangan). 
Bahasa kiasan hiperbola merupakan gaya bahasa yang mengandung suatu pernyataan yang berlebihan ditemukan pada baris kedua puluh sajak Harimau /meski taringmu berkilat-kilat/. Taring harimau digambar-kan memiliki kilau cahaya yang berlebihan.

\section{Dunia Fauna Kumpulan Puisi Jantung Lebah Ratu}

Pada pembahasan ini digunakan teori semiotika dari Riffatere. Analisis difokuskan pada pembacaan heuristik dan hermeneutik dengan ditopang matrik, dan varian. Pembacaan heuristik adalah pembacaan karya sastra (sajak) berdasarkan sistem kebahasaan (Ratih, 2016). Pembacaan hermeneutik merupakan pembacaan berdasarkan konvensi sastra. Konvensi sastra yang memberikan makna itu diantaranya konvensi ketaklangsungan ekspresi sajak yang telah diungkapkan sebelumnya (Fadli, 2015).

Penamaan sub unsur akan klasifikasi dunia fauna digunakan penamaan satwa darat, satwa tirta dan satwa dirgantara. Sistem penamaan tersebut merujuk tulisan Wibowo (1996) kajiannya berjudul Pemilihan Satwa Nasional.

\section{Satwa Tirta}

Satwa tirta adalah tema yang terdapat dalam kumpulan puisi Jantung Lebah Ratu. Sajak Cumi-Cumi, Sajak Ubur-Ubur merupakan contoh sajak yang termasuk dalam klasifikasi ini karena menggambarkan identitas eksistensi biota laut. Berikut diambil contoh analisis semiotik sajak Cumi-Cumi.

Secara heuristik sajak Cumi-Cumi memberikan penggambaran yakni cumicumi diibaratkan sebagai sebuah saputangan. Saputangan adalah benda yang digunakan untuk mengelap. Sebagai contoh pada larik /seperti saputangan ia/, /yang tekoyak di satu sudutnya/ menjelaskan saputangan yang sobek di salah satu sudutnya/. Berikutnya larik /saputangan tembus-cahaya/ menggambarkan cumi-cumi yang memiliki kemampuan mengeluarkan cahaya. Rudiana \& Pringgenies (2004) menyatakan bahwa kemampuan cumi untuk memancarkan cahaya ini disebut bioluminesensi. Bioluminesensi adalah suatu penomena pancaran cahaya tanpa mengeluarkan panas melalui proses reaksi kimia pada suatu organ organisme hidup. Selanjutnya /karena kenyang oleh air mata/ hal ini menggambarkan fungsi saputangan yang digunakan untuk mengusap air mata. Tidak diketahui mengapa cumi-cumi diibaratkan sebagai sebuah saputangan. Selanjutnya digambarkan secara spesifik perihal keberadaan cumi-cumi. Hal ini dibuktikan dengan /jemari sepuluh/ serta /mangsi hitam/ yang dimiliki oleh cumicumi.

Pembacaan hermeneutik sajak CumiCumi adalah ungkapan kekhawatir-an akan kepunahan cumi-cumi. Diksi anafora /ke mana/ yang menyimbolkan pertanyaan akan keberadaan cumi-cumi. /ke mana rangka tubuhnya/ ke mana merah dagingnya/ hal ini dirasa jelas sebab cumi-cumi merupakan biota laut yang banyak digemari oleh pecinta makanan laut (seafood). Sudjoko (1988) menyatakan bahwa selama ini konsumen utama cumi-cumi adalah bangsa Jepang. Adanya kemungkinan untuk menyindir penangkapan cumi-cumi ilegal adalah konsekuensi logis dari data yang ditemukan dalam sajak Cumi-Cumi.

Berdasarkan dua pembacaan di atas ditemukan matriks yakni eksistensi cumicumi pada eksosistem laut. Matriks tersebut terdapat tiga varian. Varian pertama adalah penggambaran hewan cumi-cumi secara deskriptif, varian kedua menggambarkan kekhawatiran akan penangkapan cumi-cumi secara illegal, ketiga adalah perumpamaan peran 
saputangan dalam kehidupan. Varian ketiga di dapat dari empat baris terakhir sajak Cumi-Cumi yakni /kukira seekor cumi-cumi/, /menjelma sehelai saputangan/, /karena ia selalu dahaga/, /akan matamu, airmatamu/ sebagai mana peran saputangan akan penggunaannya untuk mengusap air mata.

\section{Satwa Darat}

Sajak yang termasuk dalam klasifikasi ini ialah sajak Harimau, sajak Ular, dan sajak Keledai karena menggambarkan identitas eksistensi satwa darat. Berikut diambil contoh analisis semiotik sajak Harimau. Perlu diketahui harimau adalah jenis kucing terbesar dari spesiesnya, bahkan lebih besar dari singa. Harimau juga adalah kucing tercepat kedua dalam berlari setelah citah. ${ }^{1}$ Budaarsa \& Budiasa (2013) menyatakan terdapat sembilan jenis harimau di dunia, tiga jenis sudah punah, sehingga yang tersisa hanya enam jenis. Dari enam jenis yang tersisa, tiga jenis berada di Indonesia yaitu harimau sumatera (panthera tigris sumatrae), harimau (panthera tigris sondaica) dan harimau bali (panthera tigris balica). Secara heuristik sajak Harimau memberikan penggambaran dan percakapan seekor harimau dengan dirinya sendiri. Baris /dari belik gelap kau sabar menunggu aku/ menggambarkan sosok (kau) yang sedang menunggu seseorang (aku lirik). Selanjutnya adalah sosok aku lirik dihadapkan sebuah pertarungan dengan (mu) yang dihubungkan terhadap harimau. Hal ini ditemukan dari dialog /dengarlah, aku harus mengaji seribu kitab/, /sebelum bertarung denganmu/, /agar aku beroleh terang/, /untuk membalur gosong tubuhmu/, /agar aku beroleh lengang/, /untuk menawar gaung raungmu/. Sosok harimau yang buas digambarkan melalui /gosong tubuhmu/

\footnotetext{
${ }^{1}$ https://id.wikipedia.org/wiki/Harimau (diakses 3 Mei 2021)
}

dan /gaung raungmu/. Aku lirik harus belajar serius (mengaji kitab) untuk dapat "menang"/beroleh terang dan lengang/ dalam pertempuran ini. Pada baris berikutnya digambarkan sosok harimau dengan keganasannya diibaratkan dengan /kaum pecinta buta/ merupakan kaum yang tidak mengenal kata benar dan salah sebab sudah dibutakan atas cinta.

Deskripsi fisik harimau juga tidak lepas dari perhatian, misalnya terdapat bahasa kiasan hiperbola untuk menggambarkan kebringasan harimau /taringmu berkilat-kilat/. Taring si raja hutan ini dikenal buas untuk menerkam siapapun mangsanya. Akan tetapi sosok harimau ini digambarkan tidak berani menyentuh sosok aku lirik /tidak, kau tak berani menyentuh aku/kau hanya birahi/. Tampaknya sosok harimau mulai diperjelas pada larik tersebut. Birahi tersebut dikaitkan dengan larik /Ketika aku membuka baju/. Pada larik berikutnya /pandanglah tubuh yang gemetar ini/tubuh yang belum juga selesai mengaji/tubuh yang haus akan semua jalan di bumi/ sosok aku lirik digambarkan tidak mampu menghadapi sosok harimau tersebut karena belum selesai belajar.

Baris selanjutnya merupakan penggambaran kondisi setelah "akhir" yang belum usai atas pertemuan si aku lirik dengan sosok harimau. Harimau perlahan mulai pergi meninggalkan si aku lirik dengan kondisi yang tidak memungkinkan. /langkahmu ringan seperti detik $\mathrm{jam} /$, /sehingga jurangmu mengitari puncakku/, /batukku nyaring seperti topan malam/. Sang harimau pun menyangkalnya. /Tidak, kurasa akulah yang menjelang-mu/, /mengumpankan diriku/, /sebab aku takut memangsamu/ seolah memberikan arti sang harimaulah yang sedang mene-ngok si aku lirik, serta ia tidak mampu untuk melawan si aku lirik. Setelah itu si harimau seolah bercakap-cakap dengan si aku lirik. 
/percayalah, hanya kaulah yang tahu/, /jantan atau betinakah aku/, /gandrung atau dendamkah aku/ sosok harimau diceritakan yang hanya mengetahui karakter si harimau. Selanjutnya sosok harimau dikisahkan melihat cermin seolah membayangkan perasaannya atas perbuatan terhadap si aku lirik. Kembali pada kata birahi, pada larik /birahiku telah sempurna/ semakin memperjelas sosok harimau (betina). Setelah percakapan tersebut selesai si harimau perlahan pergi meninggalkan si aku lirik.

Ditinjau dari pembacaan hermeneutik sosok harimau dikisahkan sedang birahi (ingin kawin). Masa-masa tersebut rentan untuk kestabilan emosi harimau. Jika diganggu maka akan melukai orang lain. Hal itu yang digambarkan si aku lirik. Sajak Harimau di atas diceritakan tentang sosok harimau dengan cara pengungkapan dialog imajiner antara si aku lirik dengan harimau. Harimau merupakan jenis hewan buas dengan cakar dan taring yang kuat, ditambah kondisi alamiah (birahi) tentu membutuhkan pembelajaran lebih (membaca kitab) dilakukan oleh si aku lirik untuk "bertanding" dengan harimau.

Matrik dari sajak ditemukan yakni sosok harimau (betina) yang sedang birahi. Kebirahian tersebutlah mengakibatkan adanya "perseteruan" dengan si aku lirik. Berdasarkan matrik tersebut dapat ditemukan varian yakni sosok harimau ganas, birahi, dan garang yang dapat diidentifikasi dengan diksi serta ungkapan yang dilontarkan sebagai penanda kegaharan harimau. Harimau bagaimana-pun adalah binatang buas yang dapat melukai siapapun dalam keadaan terdesak atau mempertahankan diri serta menelisik mangsanya. Tampak ketika si aku lirik mendapat kerkahan dari sosok harimau tersebut. Selanjutnya adalah varian yang memberikan pemaknaan peleburan antara kebaikan dan keburukan yang ditandai pertukaran terang kulit harimau dan gelap kitab (ilmu) aku lirik. Peleburan tersebut memberikan simbol penyatuan dua jiwa yang berbeda. Secara mudah mengisyaratkan kepada kita bahwa kita dapat belajar dari siapapun tidak memandang wujud si pengajar melainkan isi hal yang disampaikan.

\section{Satwa Dirgantara}

Sajak yang termasuk dalam klasifikasi ini ialah Sajak KunangKunang, sajak Burung Merak dan sajak Lebah Ratu karena menggambarkan identitas eksistensi satwa yang bisa terbang. Berikut diambil contoh analisis semiotik sajak Lebah Ratu. Secara heuristik sajak Lebah Ratu memberi gambaran kehidupan lebah. Sebagai contoh bait pertama menggambarkan akan sebuah peristiwa yang tidak disebutkan perannya. /ribuan peminang mengepung ia setiap waktu/ merupakan peng-gambaran latar akan suatu peristiwa "peminangan" secara biologis. Jika dilihat dari segi judul maka petikan bait merujuk akan sebuah sosok yang memiliki peran "khusus" dalam perlangsungan sebuah ekosistem kehidupan. Hal itu dapat ditemukan dari adanya "hak" istimewa untuk menentukan pilihan yakni antara memuaskan atau membunuh. Oleh sebab itu, diperlukan proses seleksi koloni dan reproduksi induk secara berkelanjutan untuk dapat memperbaiki kualitas dan produktivitas koloni lebah madu (Kuntadi, 2012). Secara hermeneutik sajak Lebah Ratu melahirkan sebuah makna bagaimana kehidupan serta peran sentral lebah ratu. Proses bunuh membunuh dalam satu koloni dirasa wajar sebab hal tersebut berlaku secara alamiah untuk mendapatkan sosok pemimpin (lebah ratu) untuk dapat memimpin aspek-aspek kehidupan lebah dalam satu koloni. Lebah ratu memiliki wewenang mengatur kehidupan lebah 
jantan dan betina. Lebah jantan cenderung sedikit jumlahnya ketimbang lebah betina. Lebah jantan hanya bertugas menantarkan sperma terhadap lebah ratu. Berdasarkan kekuatan fisik yang memadai, lebah ratu dapat menyimpan sperma tersebut dengan tingkat intensitas yang lama.

Matriks yang dapat diambil ialah peran sentral dari lebah ratu dalam melangsungkan kehidupan koloni lebah. Proses kehidupan ekosistem dalam koloni lebah diceritakan secara berulang. Selanjutnya dari dua pembacaan serta matriks dapat diklasifikasikan varian. Varian pertama yakni mengisahkan akan sosok lebah ratu yang sentral dalam satu koloni lebah. Varian kedua sosok perempuan dapat menjadi figur pemimpin yang kuat, hal tersebut termanifestasi pada lebah ratu.

\section{SIMPULAN}

Dari analisis struktur bentuk dan isi ditemukan adanya permainan bunyi asonansi, aliterasi, rima dalam, dan rima akhir yang padu dengan bentuk citraan serta bahasa kiasan merupakan kekuatan utama dari segi struktur. Pembaca harus siap siaga menerima simbol-simbol yang disampai-kan oleh Nirwan dalam sembilan sajak ini. Secara keseluruhan sembilan sajak tersebut dibangun atas bentuk struktur yang kokoh dengan atribut puitik yang lengkap. Adanya pengulangan bunyi asonansi dan pengulangan bunyi konsonan aliterasi juga pemainan diksi melakui Blank Symbol, Private Symbol, dan Natural Symbol memberikan sebuah pondasi yang kuat untuk menampilkan sebuah puisi yang indah. Beragamnya unsur bahasa kiasan adalah bukti kuat untuk mewakilkan imaji yang ingin disampaikan. Selain itu ada juga perangkat citraan yang dapat digunakan untuk mengaktifkan nalar pembaca guna menggugah daya nalar dalam menciptakan romansa serta efek visualitas sajak-sajak Nirwan.

Perihal isi kesembilan sajak tidak terlepas dari konsep judul dan tidak melenceng jauh akan adanya hubungan sebab akibat judul dengan unsur yang mengiringi judul tersebut. Judul terutama menjadi pemikat sekaligus penanda akan keberadaan fauna tersebut. Dunia fauna sejatinya adalah gejala adanya ketidaklangsungan makna dalam kesembilan sajak Nirwan. Ada isi yang dapat dipetik lebih jauh, melalui idiom, metafora, serta sublimasi makna.

Dunia fauna termuat dalam kesembilan sajak yang terbagi menjadi tiga yakni satwa darat (harimau, ular, dan keledai), satwa dirgantara (kunangkunang, burung merak dan lebah ratu), dan satwa tirta (cumi-cumi, ubur-ubur, dan akuarium). Sajak Akuarium dikelompokkan ke dalam subbab fauna tirta dikarenakan merepresentasikan kehidupan ekosistem laut. Penamaan judul menjadi rujukan penting untuk mengungkap dunia fauna pada kesembilan sajak tersebut.

Penelitian ini hanya terbatas pada bentuk penelitian struktural dan analisis semiotik. Sudah tentu pula penelitian ini belum dapat mengkaji secara sempurna terhadap segala unsur yang ada dalam antologi puisi ini. Oleh karena itu, hasil penelitian ini dapat dilanjutkan oleh peneliti berikutnya dengan menganalisis dunia flora yang terdapat pada kumpulan puisi Jantung Lebah Ratu.

\section{DAFTAR PUSTAKA}

Alotia, H. (2016). Bahasa Kiasan Dalam Puisi-puisi Karya Carl Sandburg. Jurnal Elektronik Fakultas Sastra Universitas Sam Ratulangi, 2(1).

Amin, K., \& Usman, R. (2018). Anafora Dalam Puisi "Jendela Dunia "Antologi Puisi Syair Burung Beo. 
Tamaddun Life: Jurnal Bahasa, Sastra dan Budaya, 17(1), 1-3.

Atmazaki. (1993). Analisis Sajak Teori, Metodologi dan Aplikasi. Bandung: Angkasa Bandung.

Budaarsa, K., Budiasa, K. M., \& Hindu, U. (2013). Jenis Hewan Upakara dan Upaya Pelestariannya. In Makalah disampaikan pada seminar hewan upakara Fakultas Peternakan Universitas Udayana, Denpasar (Vol. 29).

Dewi, E. P. S., Atmaja, M. J., \& Triadnyani, I. G. M. (2017). Citra Pantai Bali dalam Antologi Puisi Impian Usai Karya Wayan Sunarta: Kajian Semiotik. Humanis, 19(1).

Fadli, Z. A. (2015). Kajian Semiotik: Interpretasi Puisi Kurofune Karya Kinoshita Mokutaro. Izumi, 4(2), 69-75.

Fananie, Zainuddin. (2002). Telaah Sastra. Yogyakarta: Media Pressindo.

Fitriyah, H. (2018). Asonansi dan Aliterasi Novel Safir Cinta: Dwilogi Perempuan Meniti Cahaya Karya Faradina Izdihary: Kajian Stilistika. Jurnal Sastra Aksara, 6(1), 29-40.

Gunawan, F., \& Sujinah, S. (2018). Simbol dalam Kumpulan Puisi Seribu Kekupu Karya Surachman Radea Maman. Lingua Franca: Jurnal Bahasa, Sastra, dan Pengajarannya, 2(1).

Kuntadi, (2012). Pengaruh Umur Larva Terhadap Kualitas Ratu yang Dihasilkan Pada Penangkaran Lebah Ratu Apis Cerana L. (Hymenoptera: Apidae) dengan
Teknik pencangkokan. Jurnal Entomologi Indonesia, 10 (1), (hlm 1-6).

Laila, M. P. (2016). Citraan Dalam Kumpulan Puisi Mangkutak Di Negeri Prosaliris Karya Rusli Marzuki Saria. Jurnal Gramatika, 2(1).

Meliala, R. R. S., Widodo, S. T., \& Subiyantoro, S. (2018). Analisis diksi, gaya bahasa, dan citraan dalam empat cerita anak Indonesia karya Murti Bunanta. Jurnal Pendidikan Bahasa dan Sastra, 18(1), 95-105.

PM, AA Istri Dian Anastasia, I. Ketut Sudewa, and I. GAA Mas Triadnyani. (2016). Kritik Politik Dalam Antologi Puisi Manusia Istana Karya Radhar Panca Dahana: Analisis Dan Bentuk Isi. Humanis, 17(2).

Ratih, Rina. (2016). Teori dan Aplikasi Semiotik Michael Riffatere. Yogyakarta: Pustaka Pelajar

Rudiana, E., \& Pringgenies, D. (2004). Morfologi dan Anatomi Cumi-cumi Loligo duvauceli yang Memancarkan Cahaya. Ilmu Kelautan: Indonesian Journal of Marine Sciences, 9(2), 96-100.

Saptawuryandari, N. (2013). Analisis Semiotik Puisi Chairil Anwar. Jurnal sastra dan Bahasa, 9(1), (hlm. 95-104).

Sudjoko, B. (1988). Cumi-Cumi (Cephalopoda, Moluska) Sebagai Salah Satu Bahan Makanan dari Laut. Oseana, 8(3), 97-107. 
Wibowo, Antin Siswantinah. (1996). Pemilihan Satwa Nasional. Media Konservasi, 5(1), (hlm. 41-49).

Wirandika, G. D. S. (2014) Gaya Ngurah Parsua Mengungkapkan Kritik Lingkungan Melalui Sajak "Potret Pohon Air Mata". Humanis.

Yudha, F. M., Nurizzati, N., \& Hayati, Y. (2019). Unsur bunyi dalam buku kumpulan puisi Tidak Ada New York Hari Ini karya M. Aan Mansyur. Jurnal Bahasa dan Sastra, 6(3), 276-285. 